\title{
Student as Producer: Using Research-Engaged Teaching to Enhance the Learning Experience of Biomechanics Students
}

\author{
Daniel C. Low \\ Aberystwyth University, Aberystwyth, UK
}

\begin{abstract}
With the changing landscape of the higher education system in the United Kingdom, ways in which programme teams respond to develop the curriculum, meeting the shifting demands of the student, has becomes a challenge for all those involved in teaching. Higher education should capture the interest of students and inspire them to learn, by relating the content to novel research as well as to the students' life. Lecturers should expose students to different teaching methods optimising both their understanding and their ability to apply this knowledge to different scenarios. Consequently, lecturers need to continuingly develop new ways of teaching, aiding and inspiring learning to take place. Students should have the capacity to process, apply, and critique the information given to them and then create meaning as to validity, reliability, and general usefulness of the information provided. Students should not however simply be a passive receiver of evidence but have the intellectual and practical skills to generate and create meaning from different sources of data. They should then be able to communicate these findings to different audiences through the use of different media. This helps develop intrinsic motivation and can demonstrate that deep learning has occurred. The Student as Producer (SAP) model of learning develops students through collaborative work and relates well to this philosophy. This case student demonstrates how this model of learning has been applied to enhance the learning experience of students on a Sport and Exercise Science undergraduate degree at Aberystwyth University. The aim was to develop the depth of student understanding whilst also improving the students' ability to apply the knowledge to "real world" situations; development of important work-related skills and experience was also targeted.
\end{abstract}

Keywords: Student as Producer (SAP), social learning, Sport and Exercise Science

\section{Introduction}

The current Sport and Exercise Science undergraduate degree programme at Aberystwyth University is a British Association of Sport and Exercise Science (BASES) endorsed scheme. It includes modules related to the disciplines of psychology, physiology, and biomechanics as well as modules that include research methods and academic skills development; students also participate in a work experience module. Throughout these modules, students develop their critical thinking skills and gain theoretical and practical knowledge.

Creating opportunity for partnership and collaboration where the students become the center of the learning process are important pedagogical considerations. These factors can contribute to greater student motivation and can allow deep learning to occur (Higher Education Academy [HEA], 2014). Such

Daniel C. Low, Ph.D., lecturer, Institute of Biological, Environmental and Rural Sciences, Aberystwyth University. 
considerations are fundamental components of the Student as Producer (SAP) model of learning. The model ensures that students create their own knowledge and understanding (Neary, 2010), developing skills that improve both success in formal modules and the employability of the students following graduation. Despite extra-curricular opportunities being available to the Sport and Exercise Science students at Aberystwyth University, there were limited opportunities for students to create their own understanding and develop their skills collaboratively with experts. Such lack of ownership limits students' inspiration to learn. Further still, it provided restricted development of deep understanding limiting the application of knowledge in new situations. These limitations of the current provision also limit the key critical thinking skills which is a key cross-disciplinary graduate attribute which is vital for college (university) success and employment (James, 2015).

The aim of this case study is to provide a reflective account of how the SAP concept was used within extra-curricular activities to develop partnership between students, community partners, and academics within a biomechanical setting. The case study re-frames the statement "These are contributory factors behind knee pain during running" into the question "What could be contributory factors behind knee pain during running for this client." The model of learning was then used to stimulate the application of biomechanical principles to create new knowledge and understanding in a setting that is of interest to the students. Additionally, the model of learning was used to create opportunities for students to obtain useful employability experience. Lastly, through the piloting of this model of learning in an extra-curricular setting, reflections regarding its application in formal modules can be performed.

The following objectives were then identified from these aims:

Objective 1: Use SAP to provide extra-curricular collaborative work with academics and sport therapist to enhance and inspire learning and engagement;

Objective 2: Develop knowledge of theoretical concepts and practical considerations and their application to real world settings obtaining eventual autonomy, ownership, and critical appreciation of the application process;

Objective 3: Gain work-related experience and develop employability skills, such as teamwork and inter-personal communication skills associated with working with clients and professionals.

By developing the skills and experience of students and creating a link between the university and the local community links, the aim of this case study also relate well to Aberystwyth University's vision set forward in its 2012-2017 Strategic Plan (Strategic Plan 2012-2017, n.d.). More specifically, these aims include:

Aim 1: Creating opportunities;

Aim 3: Teaching that inspires;

Aim 5: Working in partnership.

\section{Needs Analysis}

The current Sport and Exercise Science undergraduate degree programme at Aberystwyth University has been delivered since from 2002. The programme includes a wide range of discipline subjects (e.g., biomechanics, psychology, and physiology) as well as generic transferable skills-based modules (research methods and academic skills). Practical sessions are provided to develop students understanding and application of theory, but these are often not student-centered and engagement is not always maximised. This was evident when dissertation students lacked the ability to transfer knowledge taught in lectures into ability to 
collect their own research data for their thesis. Students therefore demonstrated a limited understanding of the wider application of knowledge and procedures and as a result required more input from the lecturer.

Recent emphasis on ways in which employability skills should be more thoroughly embedded into the curriculum has been made by the United Kingdom Quality Assurance Agency (QAA) for higher education (QAA, n.d.). Whilst many important employment skills are developed throughout the different modules, discussions with third-year students who were presenting a poster on how the current degree content contributes to their future career path highlighted the need to provide them with opportunities to gain applied practical experience with real clients.

The QAA also highlights the need to encourage students to participate in activities beyond that of the curriculum, helping them "make the most of their higher education experience and take responsibility for their own personal and professional development" (QAA, n.d., para. 2). Such opportunities were reasonably limited for the Sport and Exercise Science students. In addition, Aberystywth University aimed for greater community partnership and the United Kingdom HEA encouraged student-academic partnership throughout the learning process (HEA, 2014). Therefore, the intervention put forward in this case study subsequently aimed to develop extra-curricular opportunities which were in line with QAA and HEA guidance as well as being student-centered and developing real world practical experience with real clients.

\section{Theoretical Rationale}

It has been argued that teachers and lecturers should provide students with tasks and then scaffold instruction by modeling, prompting, and coaching to develop strategies for thinking and problem-solving. Such instruction gradually places the responsibility for learning on to the students. This commonly happens in a social situation and ultimately motivates the students to learn (Blumenfeld, Soloway, Marx, Krajcik, Guzdial, \& Palincsar, 1991).

Problem-solving often occurs in environments designed to learn whilst doing. In science-based programmes, this often occurs during laboratory sessions. During these sessions, students apply theory to examples which are often dictated by the tutor. Consequently, students often perceived these as passive learning environments; they are also performed on a hierarchical basis where the tutor is the knowledgeable other and the students absorb this knowledge. Mann and Robinson (2009) found the highest boredom ratings in laboratory sessions which were contrary to their initial thoughts that this would occur in lectures. The HEA (2014) also found that "students find labs tedious and boring and do not take them seriously." Further evidence from Baillie and Hazel (2003) showed that laboratory classes often consist of "controlled exercises." Such environments aim to verify student knowledge but do not create an environment where the responsibility is on the students for learning to taking place. Because of this predictability, the authors found that more able students can find these classes "dull and tedious" (Baillie \& Hazel, 2003).

SAP is a model of learning that addresses such issues. The model was developed to allow students to create knowledge through social learning (Neary \& Winn, 2009; Neary, 2010) and fundamentally relates to the core activity of university, research, and teaching, and how these concepts interlink (Neary \& Winn, 2009). Bandura (1977) described social learning as learning through the observation of other's behaviour and the consequences of their actions which SAP supports. However, it is more than students merely learning in a social context. Students are involved in research-engaged rather than research-informed curriculum, whereby in comparison to research-informed teaching (simply highlighting other research and their findings), research and 
research-like activities are at the core of the undergraduate curriculum (SAP, n.d., para. 2). This ensures that the project is in an authentic situation which helps keep the students' interest, working together with others and building real solutions. These situations also have the potential to create deep learning as students need to acquire and apply information, concepts, and principles and have the chance to improve their competence in thinking (learning and meta-cognition) as they create plans (Blumenfeld et al., 1991). Such partnership and collaboration between students, their peers, and the teacher develops student engagement which correlates with positive learning experiences and outcomes for students (Levy, 2014).

Application of the SAP model of learning is not simply about asking students to interact with one another but uses Vygotsky suggestion that a progressive educational system must be based on a progressive social context (Vygotsky, 1997). The SAP model ensures that teachers and students are collaborators in the process of education, whereby the student is in the role of "investigator who is out to establish a particular truth and whom the teacher only guides" (Vygotsky, 1997). Essentially, this turns the student-teacher relationship on its head whereby the student is no longer a passive receiver of information, but consolidates previous understanding of theory and application to actively generate new knowledge and understanding, through the tutor's guidance. As students become part of more academic projects, they produce knowledge of real academic value (Neary \& Winn, 2009) which again offers potential for a more authentic engagement with the nature of learning itself and the possibility for genuinely transformative learning experiences for all involved (Healey, Flint, \& Harrington, 2014).

An important aspect of the collaborative interaction is that students take ownership in their learning, and can actively relating concepts to important factors in their own life. Sullivan and Van Riel (2013) found that developing the link between module topic and the students' life helps bring confidence and success by inspiring the students to engage their time in reading and participating in future activities that aid learning. Consequently, by taking ownership, collaborative working, and making the students the center of the learning process, the students will become more autonomous over time. Maslow $(1943 ; 1954)$ described that working with autonomy helps build self-actualisation which is an important component to stimulate internal motivation needed for learning to occur (Deakin-Crick, Sebba, Harlen, Guoxing, \& Lawson, 2005). Students then progress through the zone of proximal development to a zone where by the students can "do" without guidance (Vygotsky, 1978).

In addition to the greater cognitive development, if the setting in which collaborative work takes place replicates real world scenarios, it can also be used to improve student employability. Harvey (2003) described that:

Employability is more than about developing attributes, techniques or experience just to enable a student to get a job, or to progress within a current career. It is about learning and the emphasis is less on "employ" and more on "ability." In essence, the emphasis is on developing critical, reflective abilities, with a view to empowering and enhancing the learner.

Preparing students to match the changes in society and to prepare future citizens for continued learning throughout life cannot be achieved by direct teaching. Students learn these things through reflection and meta-cognitive development (Hattie, Biggs, \& Purdie, 1996, as cited in Black \& Wiliam, 1998). It requires a relationship between teachers and students in which students are helped to take responsibility for their learning and a view of learning which places learners at the centre of the process (Deakin-Crick et al., 2005). Therefore, the application of SAP and learning in a social collaborative setting lends itself to improving knowledge and 
understanding as well as developing employability skills, such as teamwork and communication in "real world" settings.

The combined beneficial effect on learning through social interaction, partnership, and research-engaged learning develops the students, building greater confidence and an improved motivation to learn. Whilst the theoretical approach has been utilised to enhance the learning of students in the area of sports coaching (Keegan, 2010), it is yet to be established whether the approach can be successfully used with sports biomechanics students in a laboratory setting with real clients.

\section{The Intervention}

The SAP intervention, set within the discipline of sport and exercise biomechanics, was split into five stages:

Stage 1: Initial observation;

Stage 2: Data collection process;

Stage 3: Processing of data;

Stage 4: Full gait analysis;

Stage 5: Evaluation of the learning and experience.

This case study recruited students who volunteered to take part in each stage. All participants were aware that the intervention was extra-curricular and did not contribute towards their degree classification. They were, however, also aware that participation could enhance the knowledge and contribute to better performance in the formal degree curriculum. They were also aware that they could drop out at any time without consequence. All second (Level 5) and third (Level 6) year students were able to take part in the sessions regardless of their performance in other biomechanics modules. All students were sent an email detailing the opportunity to work with an academic, sports therapist, and their client. They were made aware that they were to assess the running gait with the aim of identifying any unusual characteristics that may be associated with their pain or injury. This opportunity aimed to complement the content taught at Level 6 and extend the knowledge and skills taught at Level 5.

A total of 10 students took the opportunity to participate in four practical sessions with different clients. The sessions were arranged so that the students developed their understanding through progressively more challenging and independent consultation. During the sessions, the students developed their understanding and application of client confidentiality, whereby the information and data provided by the clients was fully password-protected and anonymous with only the student, sports therapist, and academic knowing the clients specific details. The students were also given individual feedback on their individual performance throughout each session as well as how well they worked as a team and with the client.

In the first session, the students mostly observed the procedures, but did gain practical experience regarding how to work the motion analysis system, the different marker placement location, and the reasons behind their positioning. They also learnt how to communicate with the client appropriately.

Before the second session, the students were asked to practice the testing procedure observed in session one, setting up the analysis system before the clients arrived, which provided the opportunity to reflect and consider the best way to go about this task. They then prepared the client with the markers needed for the analysis, justifying their placement to the lecturer during discussions.

In the third session, the students were more autonomous, setting up the equipment and prepared the clients before the lecturer collected the data. They then explained the details behind the set-up to the researcher. In the 
final session, the students demonstrated their collection skills to gather evidence. This evidence was compared to literature "norms" for injured and uninjured population. This helped them develop understanding behind "What could be contributory factors behind knee pain during running for this client?"

Throughout the sessions, the lecturer rigorously monitored the processes used during the assessment to ensure both the safety of those involved and the integrity of the data provided. All analysis and interpretation were thoroughly checked and approved by the lecturer or modified if appropriate before the interpretation was given to the sport therapist.

In the final session, the aims of the application of SAP were assessed via a student questionnaire. The questionnaire (see Appendix) asked questions on a 5-point scale which ranged from "Completely disagree" (1) to "Completely agree" (5). Conversations with the sports therapist were also used to evaluate the success of the approach.

\section{Impact of SAP and Reflections on the Application of the Model of Learning}

Within this case study, the SAP model of learning was used to provide extra-curricular opportunities where collaborative work with an academic could take place. This approach aimed to enhance and inspire learning and improve engagement in the learning of biomechanics. The model of learning was also used in an attempt to allow students to be at the center of their own learning, creating meaning of lower limb injury in a situation that they had an interest. This case study showed that through social learning, this aim could be achieved. The social learning environment promoted a research-engaged approach ensuring that students were "active" in their learning, which helped the students take ownership of in a situation of interest to the students. The students were engaged in the process as they volunteered to take part in multiple assessment sessions as well as practicing the set-up of the equipment in their own time. This demonstrated an internal motivation to learn. The social situation also encouraged discussion where the students were able to explain their reasoning and demonstrate deep understanding.

It was clear that the students became collaborative partners of the academic projects, learning through the interaction with the lecturer to create knowledge relating to possible causes of the clients' symptoms. Feedback indicated that the students "Agreed" or "Completely agreed" that, by the end, they felt like a partner in the process and not a student following the lead of the lecturer (average of 4 out of 5) (4= "Agreed" and $5=$ "Completely agreed").

Student engagement, as highlighted by Levy (2014), correlated with positive learning experiences for the students. The students expressed that they enjoyed learning through the approach. Evaluations showed that the students felt that the approach should be "a module alongside the Biomechanical Analysis [module]." Other students suggested that it should be taught "as a module" and that the approach was "very good" and which "would be nice to have some more sessions like this in other modules because it was a great way to learn." Quantitative data also demonstrated that the students found the approach was useful in their learning and showed desire for similar opportunity in other disciplines scoring an average of 4.75 out of 5 in the quantitative feedback.

Following the sessions, correspondence with the sports therapist highlighted that the data and its interpretation generated by the students were valued, stating that "the information is extremely useful." The data provided also ensured the case studies based on the injury of the client and their symptoms could be collated. These case studies can be used to inspire the SAP students as they see that they had contributed to 
changing people's lives. It would also help other students see that their peers who are similar to them produced a meaningful contribution to knowledge and understanding. This would motivate them to learn and participate in extra-curricular activities. However, it is important to acknowledge that students need to be involved in research-engaged rather than research-informed curriculum (SAP, n.d., para. 2). Therefore, new opportunities for SAP to take place require continuous development.

Another aim of the case study was to develop knowledge of the theoretical concepts and practical considerations and their application to real world settings. It was hoped that this would lead into the students obtaining eventual autonomy, ownership, and critical appreciation of their application process. The SAP model of learning was used to successfully help the students progressively develop practical skills from basic level to that which the students could collect data independently on "real world" clients. It was clearly evident that the students were more confident as the sessions passed. Student evaluation supported the researcher's observations. The students felt that they developed subject specific skills including understanding the procedures for collecting biomechanical data (average of 4 out of 5) and felt that they were more confidence in performing the assessment on their own (average of 3.75 out of 5). Further still, the students felt that they could interpret the data with some help (average of 4 out of 5). Such evidence highlights that the SAP model of learning can be used within Sport and Exercise Science to improve learning.

Due to the evidence that showed that students could perform the analysis on their own, it was clear that students were autonomous, which as Maslow $(1943 ; 1954)$ identified as indicative of deep learning taking place. Some of the students also showed the ability to work without guidance in a formal module where the students supported a lecturer in some laboratory sessions. The students demonstrated to their peers their level of understanding of the equipment and how it can be used. The ability to offer peer learning is important since it deepens the knowledge gained by the SAP students. It also provides room for critical reflection and improves the ability to communicate and articulate knowledge, understanding, and skills (Boud, 2001). As a response, the SAP students feel successful and that they have made progress. It also motivates the peer students by the fact that they can see people similar to them understand and apply the subject matter. This is in line with Bandura's (1977) social learning theory and will increase other students' intrinsic motivation to learn.

Whilst the learning experience of the students was enhanced, more student autonomy could have been introduced. This would prevent boredom particularly in the more able students (Baillie \& Hazel 2003). Therefore, future sessions could also be student-led. For example, students could be asked to place the markers on a person without any guidance or direction from the lecturer. They would then look at the effect on the data provided. Similarly, it was hoped that students would develop their critical thinking skills through the process of the sessions. This is a particular skill required for a student at Level 6 . However, for the students to thoroughly critique the process, additional information delivered through extra sessions would have been needed. For example, smoothing and filtering of the data and the effect on the interpretation were not introduced. This element of learning therefore remains shallow because when asked why they used the filter, the student responded with "It is because I was told to do it." Future sessions could therefore be student-led, by looking at the effect of marker smoothing, creating their own understanding of the effect of errors on the data. Through discussions with a lecturer, a relationship between the student and teacher is developed and helps the students take responsibility for their learning, placing them at the centre of the process (Deakin-Crick et al., 2005). The discussions that would follow from these discussions would then contribute to critical thinking skills being developed (Blumenfeld et al., 1991). In this way, a series of sessions could be created changing the 
social context of the module and contribute to a change in the institution itself through progressive pedagogic practice, a key aim of the model of learning (Neary, 2010).

Lastly, the case study aimed to develop students' employability skills. The researcher felt that following their experience of working with the clients, the students were able to clearly and confidently discuss the procedures with both a specialist (lecturer) and non-specialist (client and sport therapist) audiences, an important Level 6 QAA benchmark statement requirement (QAA, 2008). The students also developed inter-personal communications skills when working with clients and their peers, demonstrating a clear rapport and appropriately discussing the marker placement; they then tactfully identified and placed markers on the client.

The students also showed that they could work as part of a team, taking responsibility for their role in the assessment of the individual and also showed dedication and tenacity to learn by engaging in the organised sessions and then additionally practicing in their own time. The students were also able to discuss the importance of confidentiality which is a key ethical concern and widens their application of such consideration.

Student evaluations demonstrated that they "Agreed" or "Completely agreed" that the experience enhanced employment skills, which will be added to their CV (average of 4.75 out of 5). They also suggested that the opportunity was valuable to get a job (average of 4 out of 5) and provided practical skills in a real life setting (average of 4.5 out of 5). The approach was seen as "really helpful and [a] positive experience" and that they would "definitely do it again." In such additional opportunities, one should utilise the experience presented in this case study, providing extra-curricular activities that are developed with the limitations described in study in mind.

\section{Conclusion}

The use of social learning is not a new concept. The use of collaborative partnership in laboratory sessions is however not often seen. Within this case study, it is clear that SAP can work effectively to create an opportunity for the student to engage in the application of theory and to create knowledge and understanding for themselves. In addition, the use of SAP can improve employability-related skills and holistically offers a greater student experience.

In line with the concept's aim of transformation of the curriculum (Neary, 2010), it is aimed that SAP will be introduced where possible into the formal curriculum. This case study piloted the model of learning and clearly demonstrated that students were inspired to learn through this approach. Future sessions could therefore be created to develop the critical understanding and application of knowledge in different disciplines, as well as improving the communication skills of the students to different audiences. These are important Level 6 benchmark statements.

\section{References}

Baillie, C., \& Hazel, E. (2003). Teaching materials laboratory classes. Retrieved from http://www.materials.ac.uk /guides/9-lab-classes.pdf

Bandura, A. (1977). Social learning theory. Englewood Cliffs, N.J.: Prentice Hall.

Black, P., \& Wiliam, D. (1998). Inside the black box. London, U.K.: King's College London School of Education.

Blumenfeld, P. C., Soloway, E., Marx, R. W., Krajcik, S. J., Guzdial, M., \& Palincsar, A. (1991). Motivating project based learning: Sustaining the doing, supporting the learning. Educational Psychologist, 26(3\&4), 369-398.

Boud, D. (2001). Introduction: Making the move to peer learning. In D. Boud, R. Cohen, \& J. Sampson (Eds.), Peer learning in higher education: Learning from and with each other. London, U.K.: Kogan Page. 
Deakin-Crick, R., Sebba, J., Harlen, W., Guoxing, Y., \& Lawson, H. (2005). Systematic review of research evidence of the impact on students of self- and peer- assessment research evidence in education library. London, U.K.: EPPI-Centre, Social Science Research Unit, Institute of Education, University of London.

Harvey, L. (2003). Transitions from higher education to work. Retrieved from http://www.qualityresearchinternational.com/ esecttools/esectpubs/harveytransitions.pdf

Hattie, J., Biggs, J., \& Purdie, N. (1996). Effects of learning skills interventions on student learning: A meta-analysis. Review of Educational Research, 66, 99-136.

Healey, M., Flint, A., \& Harrington, K. (2014). Engagement through partnership: Students as partners in learning and teaching in higher education. York: HEA.

Higher Education Academy (HEA). (2014). Framework for partnership in learning and teaching in higher education. York: HEA.

James, R. (2015). Evaluation of critical thinking in higher education in Oman. International Journal of Higher Education, 4(3), 3.

Keegan, R. (2010). Student-as-producer: Reflections on a 6-week trial aimed at producing scientist-practitioners in sport coaching (Unpublished manuscript, University of Lincoln).

Levy, P. (2014). Foreword. In M. Healey, A. Flint, \& K. Harrington (Eds.), Engagement through partnership: Students as partners in learning and teaching in higher education. York: HEA.

Mann, S., \& Robinson, A. (2009). Boredom in the lecture theatre: An investigation into the contributors, moderators and outcomes of boredom amongst university students. British Educational Research Journal, 35(2), 243-258.

Maslow, A. H. (1943). A theory of human motivation. Psychological Review, 50(4), 370-396.

Maslow, A. H. (1954). Motivation and personality. New York, N.Y.: Harper and Row.

Neary, M. (2010). Student as producer: A pedagogy for the avant-garde? Learning Exchange, 1.

Neary, M., \& Winn, J. (2009). The student as producer: Reinventing the student experience in higher education. In L. Bell, M. Neary, \& H. Stevenson (Eds.), The future of higher education: Pedagogy, policy and the student experience (pp. 192-210). London, U.K.: Continuum.

Quality Assurance Agency (QAA). (2008). The framework for higher education qualifications in England, Wales and Northern Ireland. York: HEA.

QAA. (n.d.). In Skills for employability. Retrieved from http://www.qaa.ac.uk/assuring-standards-and-quality /skills-for-employability

Strategic Plan 2012-2017. (n.d.). In Aberystwyth University Strategic Plan 2012-2017 Webpage. Retrieved from https://www.aber.ac.uk/en/strategicplan/

Student as Producer (SAP). (n.d.). In The University of Lincoln, Educational Development and Enhancement Unit Webpage. Retrieved from http://edeu.lincoln.ac.uk/student-as-producer/

Sullivan, P., \& Van Riel, N. (2013). Building confidence and fostering engagement in aboriginal learners. In R. Jorgensen, P. Sullivan, \& P. Grootenboer (Eds.), Pedagogies to enhance learning for Indigenous students (pp. 139-153). Singapore: Springer.

Vygotsky, L. (1997). Education psychology. Boca Raton, F.L.: St Lucie Press. 


\section{Appendix: Gait Analysis Feedback}

Following helping the analysis of two or more participants, please can you complete the following feedback questionnaire.

I completed observations and gait analyses. I am in year of study.

\begin{tabular}{|c|c|c|c|c|c|}
\hline I now feel that I understand the procedures for collecting biomechanical data. & 1 & 2 & 3 & 4 & 5 \\
\hline I feel confident in performing similar assessment on my own. & 1 & 2 & 3 & 4 & 5 \\
\hline I feel that I can interpret the data with some or little help. & 1 & 2 & 3 & 4 & 5 \\
\hline I feel that I can now report information back to the client effectively. & 1 & 2 & 3 & 4 & 5 \\
\hline I feel that reporting back data to the client rewarding. & 1 & 2 & 3 & 4 & 5 \\
\hline The content level is correct. & 1 & 2 & 3 & 4 & 5 \\
\hline I feel that I got valuable practical skills in a real life setting. & 1 & 2 & 3 & 4 & 5 \\
\hline I feel that there was an appropriate level of independence. & 1 & 2 & 3 & 4 & 5 \\
\hline I feel I took ownership of the process in later analysis. & 1 & 2 & 3 & 4 & 5 \\
\hline I was able to choose an appropriate analysis for the situation without need for consultation with the lecturer. & 1 & 2 & 3 & 4 & 5 \\
\hline I feel like a partner in the process and not a student following the lead of a lecturer. & 1 & 2 & 3 & 4 & 5 \\
\hline I feel that more training could have been valuable. & 1 & 2 & 3 & 4 & 5 \\
\hline I feel that there was an appropriate level of support. & 1 & 2 & 3 & 4 & 5 \\
\hline I feel that this opportunity will help me with my current module. & 1 & 2 & 3 & 4 & 5 \\
\hline I feel that this opportunity will help me with future study. & 1 & 2 & 3 & 4 & 5 \\
\hline I feel that this knowledge helped with the understanding of future lecturers attended. & 1 & 2 & 3 & 4 & 5 \\
\hline I feel more knowledgeable about the topic of biomechanics than after similar lectures. & 1 & 2 & 3 & 4 & 5 \\
\hline I will you add this experience to my CV? & 1 & 2 & 3 & 4 & 5 \\
\hline This was a valuable experience that will help me get a job. & 1 & 2 & 3 & 4 & 5 \\
\hline I would take this opportunity again if it was given to me. & 1 & 2 & 3 & 4 & 5 \\
\hline It would be useful if there were similar projects used for other disciplines. & 1 & 2 & 3 & 4 & 5 \\
\hline The presentation back to the group was a good experience. & 1 & 2 & 3 & 4 & 5 \\
\hline
\end{tabular}

Notes. 1 = "I completely disagree"; 2 = "I disagree"; 3 = "I neither agree nor disagree"; 4 = "I agree"; and 5 = "I completely agree."

Is there anything else you would like to add?

What could be improved about the sessions? 